\title{
Early weaning causes undernutrition for a short period and programmes some metabolic syndrome components and leptin resistance in adult rat offspring
}

\author{
Natália da Silva Lima ${ }^{1}$, Egberto Gaspar de Moura ${ }^{1}$, Magna Cottini Fonseca Passos ${ }^{2}$, José Firmino \\ Nogueira Neto ${ }^{1}$, Adelina Martha Reis ${ }^{3}$, Elaine de Oliveira ${ }^{1}$ and Patricia Cristina Lisboa ${ }^{1}$ * \\ ${ }^{1}$ Departamento de Ciências Fisiológicas - $5^{\circ}$ Andar, Instituto de Biologia Roberto Alcantara Gomes, Universidade do Estado \\ do Rio de Janeiro, Avenue 28 de Setembro, 87-Rio de Janeiro, RJ 20551-030, Brazil \\ ${ }^{2}$ Departamento de Nutrição Aplicada, Instituto de Nutrição, Universidade do Estado do Rio de Janeiro, Rio de Janeiro, Brazil \\ ${ }^{3}$ Department of Physiology and Biophysics, Federal University of Minas Gerais, MG, Brazil
}

(Received 12 February 2010 - Revised 4 August 2010 - Accepted 5 August 2010 - First published online 28 January 2011)

\section{Abstract}

Maternal malnutrition during lactation programmes for overweight and central leptin resistance in adulthood. The inhibition of lactation by maternal treatment with bromocriptine (a prolactin inhibitor) programmes for obesity, hyperleptinaemia and leptin resistance. Here, we evaluated the short- and long-term effects of early weaning (EW) on body-weight regulation, leptin signalling, and hormone and lipid profiles in rats offspring. Lactating rats were separated into two groups: EW - dams were wrapped with a bandage to interrupt the lactation in the last $3 \mathrm{~d}$ of lactation; control - dams whose pups had free access to milk during all lactation ( $21 \mathrm{~d})$. Data were significant at $P<0 \cdot 05$. At weaning, EW pups presented lower body weight (-10\%), length $(-4 \%)$, visceral fat $(-40 \%)$, total fat $(-30 \%)$, serum leptin $(-73 \%)$, glycaemia $(-10 \%)$, serum insulin $(-20 \%)$ and insulin resistance index (IRI; $-30 \%)$, but higher total body protein content $(+40 \%)$. At $180 \mathrm{~d}$, EW offspring showed hyperphagia, higher length $(+3 \%)$, body weight $(+8 \%)$, visceral and total fat $(+36$ and $84 \%)$, serum TAG $(+96 \%)$, glycaemia (+15\%), leptinaemia (+185\%) and IRI (+29\%); however, they showed lower total protein content ( $-23 \%)$, leptin:body fat ratio (41\%), prolactinaemia $(-38 \%)$ and adiponectinaemia $(-59 \%)$. Despite unchanged leptin receptor (OB-R) and signal transducer and activator of transcription 3 (STAT3), they displayed lower hypothalamic janus tyrosine kinase 2, phosphorylated STAT3 and a higher suppressor of cytokine signalling 3 levels, suggesting a central leptin resistance. Adult rats that were early weaned displayed higher adiposity, insulin resistance and dyslipidaemia, which are related to metabolic syndrome development. Our model reinforces the idea that neonatal malnutrition caused by shortening of the lactation period is important for metabolic programming of future diseases.

Key words: Early weaning: Metabolic syndrome: Body fat mass: Hormones

According to the $\mathrm{WHO}^{(1)}$, 'exclusive breast-feeding is defined as no other food or drink, not even water for 6 months of life'. Exclusive and prolonged breast-feeding has also been associated with protection against long-term chronic diseases such as obesity and diabetes ${ }^{(2)}$. However, no more than $35 \%$ of infants worldwide are exclusively breastfed during the first 4 months of life ${ }^{(3)}$.

Directly or indirectly, malnutrition has been responsible for $60 \%$ of the 10.9 million deaths among children annually ${ }^{(3)}$. Barker et $a l .{ }^{(4)}$ has associated low birth weight with diseases related to the metabolic syndrome (obesity, diabetes and hypertension) in adulthood. Additionally, our group has showed that adverse situations during lactation, such as malnutrition and hormonal changes, could permanently affect the nutritional and hormonal status of the progeny ${ }^{(5-12)}$ This association has been denominated metabolic programming, which is defined as a biological phenomenon that determines the relationship between physical and chemical stimuli in critical periods of early life, such as gestation and lactation, with future functional status ${ }^{(13-16)}$

During lactation, maternal energy restriction programmes for overweight without altering food intake ${ }^{(17)}$, and leptin resistance to its anorexigenic effect in adult offspring ${ }^{(18)}$. In lactating rats, undernutrition is associated with a failure in milk production ${ }^{(17)}$ caused by hypoprolactinaemia ${ }^{(19)}$. Also, the inhibition of the last $3 \mathrm{~d}$ of lactation through maternal

Abbreviations: EW, early weaning; IRI, insulin resistance index; JAK2, janus tyrosine kinase 2; PRL, prolactin; SOCS3, suppressor of cytokine signalling 3; STAT3, signal transducer and activator of transcription 3; VFM, visceral fat mass.

* Corresponding author: Dr P. C. Lisboa, fax +5521 25876129, email patricialisboa@pq.cnpq.br 
treatment with bromocriptine (a prolactin (PRL) inhibitor) caused milk production inhibition, neonatal malnutrition evidenced by lower body weight of weaned pups ${ }^{(20)}$ as well as programmed for obesity, hyperleptinaemia, central leptin resistance $^{(21)}$, higher TAG and cholesterol in adulthood ${ }^{(22)}$, and secondary hypothyroidism ${ }^{(23)}$. However, in this model, it is difficult to separate the effects of maternal hypoprolactinaemia from those of decrease in milk ingestion. On the other hand, recently, it has been observed that maternal moderate energy restriction during lactation was associated with beneficial effects in their offspring, such as lower bodyweight gain and fat accumulation under a high-fat diet ${ }^{(24)}$.

Leptin, a hormone mainly produced by adipocytes, acts through leptin receptors (OB-R) to inhibit food intake and stimulate energy expenditure by specific hypothalamic signals, and only its long form OB-Rb is capable of active intracellular signalling ${ }^{(25)}$. Leptin binding to OB-Rb initiates tyrosine phosphorylation by janus tyrosine kinase 2 (JAK2). Phosphorylated JAK2 recruits signal transducer and activator of transcription 3 (STAT3) proteins, which are activated through phosphorylation. Activated STAT3 dimerises and translocates to the nucleus, where it stimulates gene transcription. The JAK2/ STAT3 pathway stimulates the transcription of suppressor of cytokine signalling 3 (SOCS3), a leptin-inducible inhibitor of the leptin signalling pathway ${ }^{(26,27)}$. In obese individuals, hyperleptinaemia does not cause satiety and increases energy expenditure, as expected. This is explained by leptin resistance, caused by the down-regulation of $\mathrm{OB}-\mathrm{R}^{(28,29)}$, by an impairment of the intracellular signalling pathway ${ }^{(30,31)}$ or by a reduced blood-brain barrier transport ${ }^{(32,33)}$.

Then, in order to know whether precocious weaning can programme for endocrine and metabolic dysfunctions, the present study was designed to evaluate the immediate and late repercussion of lactation interruption without the use of pharmacological substances or maternal separation upon food intake, body length and composition, lipid profile, leptin, insulin and adiponectin levels, expression of proteins of the leptin signalling pathway in the hypothalamus and glucose homeostasis in rat offspring.

\section{Experimental methods}

The use of the animals according to our experimental design was approved by the Animal Care and Use Committee of the Biology Institute of the State University of Rio de Janeiro (CEA/017/2009), which based its analysis on the principles adopted and promulgated by Brazilian Law (no. 11.794/ 2008). Experiments were conducted to minimise the number of animals and the suffering caused by the procedures following the ethical doctrine of the three 'R's' - reduction, refinement and replacement ${ }^{(34,35)}$.

Wistar rats were kept in a temperature-controlled room $\left(23 / 24^{\circ} \mathrm{C}\right)$ with artificial dark-light cycles (lights on 07.00 hours and lights off 19.00 hours), Virgin female rats, 3 months old, were caged with male rats at a proportion of 3:1. After mating, each female was placed in an individual cage with free access to water and food until delivery. We used only the dams whose litter size was ten pups in order to avoid the influence of litter size in the programming effect. At birth, to maximise lactation performance ${ }^{(17)}$, litters were adjusted to six male pups/dam.

\section{Experimental model of early weaning}

After birth, twelve lactating rats were randomly separated into two groups: early weaning (EW, $n$ 6) - dams were lightly anaesthetised with thiopental $(0.06 \mathrm{mg} / \mathrm{ml}$ per $100 \mathrm{~g})$ and wrapped with a bandage to interrupt the lactation in the last $3 \mathrm{~d}$ of lactation; control ( $n$ 6) - dams whose pups had standard lactation period, i.e. weaning occurred at $21 \mathrm{~d}$ of lactation. Both groups received food directly into the cage, and the pups had easy access to a drinking-water bottle.

During lactation, body weight and the naso-anal length of pups were daily monitored. After weaning, EW and control offspring had free access to water and a standard diet, and their body weight, food intake and body length were recorded. Relative food intake was measured by dividing food intake by body weight. We used two offspring from each dam, which were killed at 21 or $180 \mathrm{~d}$ after $12 \mathrm{~h}$ of fasting. The killing occurred by quick decapitation, with no prior anaesthesia (because anaesthesia affects hormone and lipid metabolism), to collect blood, carcass, visceral fat mass (VFM) and hypothalamus.

Body composition evaluation. On the day of killing, VFM was excised (mesenteric, epididymal and retroperitoneal white adipose tissue) and immediately weighed for evaluation of central adiposity. Total body fat and protein contents were determined by carcass analysis ${ }^{(36,37)}$. Pups were eviscerated; the carcass was weighed, autoclaved for $1 \mathrm{~h}$ and homogenised on distilled water $(1: 1)$. The homogenates were stored at $4^{\circ} \mathrm{C}$ for analysis.

The homogenate $(3 \mathrm{~g})$ was used to determine fat content gravimetrically. Samples were hydrolysed on a shaking water-bath at $70^{\circ} \mathrm{C}$ for $2 \mathrm{~h}$ with $30 \% \mathrm{KOH}$ and ethanol. Total fatty acids and non-esterified cholesterol were removed with three successive washing with petroleum ether. After drying, overnight in vacuum, tubes were weighed, and data are expressed as $\mathrm{g}$ of fat/100 $\mathrm{g}$ of carcass.

Protein content was determined in $1 \mathrm{~g}$ of the homogenate. Tubes were centrifuged at $2000 \mathrm{~g}$ for $10 \mathrm{~min}$. Total protein concentrations were determined by the Lowry method ${ }^{(38)}$. Data are expressed as $\mathrm{g}$ of protein/100 $\mathrm{g}$ of carcass.

Western blot analysis. To obtain cell extracts, the hypothalamus was homogenised in ice-cold lysis buffer

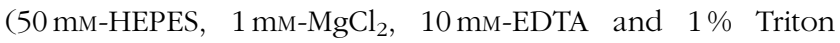
$\mathrm{X}-100, \mathrm{pH}$ 6.4) containing the following protease inhibitors: aprotinin $(10 \mu \mathrm{g} / \mu \mathrm{l})$, leupeptin $(10 \mu \mathrm{g} / \mu \mathrm{l})$, pepstatin $(2 \mu \mathrm{g} / \mu \mathrm{l})$ and $1 \mathrm{~mm}$-phenylmethylsulphonyl fluoride (Sigma-Aldrich, St Louis, MO, USA). After centrifugation ( $7500 \boldsymbol{g}$ for $5 \mathrm{~min}$ ), the homogenates were stored at $-20^{\circ} \mathrm{C}$. OB-R (a leptin receptor), JAK2, STAT3, phosphorylated STAT3 and SOCS3 contents were analysed by Western blot as described previously ${ }^{(12)}$, using actin as the internal control.

Briefly, protein concentrations were determined by the bicinchoninic acid Protein Assay Kit (Thermo Scientific, Rockford, IL, USA). Samples ( $30 \mu \mathrm{g}$ of total protein) were 
separated by $10 \%$ SDS-PAGE according to the molecular weight of each protein, and transferred to nitrocellulose membranes (Hybond ECL; Amersham Pharmacia Biotech, Amersham, London, UK). Rainbow standard markers (Amersham Biosciences, Uppsala, Sweden) were run in parallel to estimate molecular weights. The membranes were blocked with 5\% non-fat milk in Tween-Tris-buffered saline (20 mm-Tris-HCl, pH 7·5, $500 \mathrm{~mm}-\mathrm{NaCl}$ and $0 \cdot 1 \%$ Tween-20) for $1 \mathrm{~h}$. Specific primary antibodies (Santa Cruz Biotechnology, Inc., Santa Cruz, CA, USA) used were anti-OB-R, anti-JAK2, anti-STAT3, anti-phosphorylated STAT3, anti-SOCS3 and anti-actin. The membranes were incubated with primary antibodies at 1:500 dilution in Tween-Tris-buffered saline buffer for $1 \mathrm{~h}$, with an appropriate secondary antibody (1:10000, peroxidase-conjugated IgG; Santa Cruz Biotechnology) for $1 \mathrm{~h}$ and then with streptavidin (1:10000; Zymed, San Francisco, CA, USA) for $1 \mathrm{~h}$. The targeted proteins were detected by enhanced chemiluminescence (Amersham Pharmacia Biotech, Piscataway, NJ, USA) and then exposed to X-ray film for $10 \mathrm{~s}$ to $30 \mathrm{~min}$. The images were scanned, and the bands were quantified by densitometry using Image J $1.34 \mathrm{~s}$ software (Wayne Rasband National Institute of Health, MA, USA).

Hormonal determination by RIA. Blood samples were centrifuged $\left(1500 \mathrm{~g}\right.$ for $20 \mathrm{~min}$ at $4^{\circ} \mathrm{C}$ ) to obtain serum, which was frozen $\left(-20^{\circ} \mathrm{C}\right)$ until analysis. All measurements were performed in one assay. Leptin was measured with a specific RIA kit (Linco Research, Inc., St Charles, MO, USA), which measures both rat and mouse leptin with a range of detection from 0.5 to $50 \mathrm{ng} / \mathrm{ml}$; intra-assay variation was $2.9 \%$. Insulin concentration was determined using an RIA kit (ICN Pharmaceuticals, Inc., Orangeburg, NY, USA), with an assay sensitivity of $0 \cdot 1 \mathrm{ng} / \mathrm{ml}$ and an intra-assay variation of $4 \cdot 1 \%$. Adiponectin was measured with a specific RIA kit (Linco Research), with an assay sensitivity of $0.5 \mathrm{ng} / \mathrm{ml}$ and an intra-assay variation of $7 \cdot 1 \%$. PRL was determined by a specific RIA using reagents supplied by the National Institute of Health (MD, USA). Data are reported in ng from the reference preparation RP-3 with an assay sensitivity of $0.3 \mathrm{ng} / \mathrm{ml}$ and an intra-assay coefficient of $8 \%$.

Insulin sensitivity. Fasting blood glucose was determined from the tail vein of fasting rats using a glucosimeter (ACCUCHEK $^{\circledR}$ Advantage; Roche Diagnostics, Mannheim, Germany). To determine the insulin sensitivity of adult animals, we used the insulin resistance index (IRI): fasting glycaemia $(\mathrm{mg} / \mathrm{l}) \times$ fasting insulinaemia $(\mu \mathrm{IU} / \mathrm{ml})$.

Lipid profile analysis. Serum levels of total cholesterol, TAG and HDL-cholesterol were analysed using Biosystem commercial test kits with an automated A15 spectrophotometer (Biosystems S.A., Barcelona, Spain). LDL-cholesterol and VLDL-cholesterol were calculated according to the equation of Friedwald:

$$
\text { VLDL-cholesterol }=\mathrm{TAG} / 5 \text {. }
$$

$$
\text { LDL-cholesterol }=(\text { total cholesterol }-\mathrm{HDL}-\mathrm{C}-\mathrm{TAG}) / 5 \text {. }
$$

Statistical analysis. Results are reported as means with their standard errors. Statistical analyses and graphics were performed using the GraphPad Prism 4 (GraphPad Software, Inc., La Jolla, CA, USA) program. Leptin signalling was analysed by the non-parametric Mann-Whitney $U$ test. Other experimental data were analysed by Student's unpaired $t$ test, with the level of significance set at $P<0.05$.

\section{Results}

At $21 \mathrm{~d}$, EW pups presented lower body weight $(-10 \%$, $P<0.05)$ and naso-anal length $(-4 \%, P<0.05)$ compared with the group normally weaned, as shown in Fig. 1. At $180 \mathrm{~d}$, EW offspring showed higher body weight $(+8 \%$, $P<0.05)$, higher body length $(+3 \%, P<0.05)$ as well as persistent hyperphagia, as shown in Fig. 2.

As depicted in Table 1, the 21-d-old EW pups had lower total body fat $(-29.7 \%, P<0.05)$, lower VFM $(-40 \%$, $P<0.05)$, but higher total protein content $(+40 \%, P<0.05)$. In adulthood, these animals showed higher total fat mass $(+36 \%, P<0.05)$, higher VFM $(+84 \%, P<0.05)$ and lower body protein mass $(-22.5 \%, P<0.05)$. Juvenile EW offspring presented hypoleptinaemia $(-73 \%, P<0.05)$, but adult EW offspring showed hyperleptinaemia $(+185 \%, P<0.05)$. At $180 \mathrm{~d}$, the leptin:body fat ratio was lower in the EW group ( $-41 \%$, control: 0.123 (sem 0.016), EW: 0.072 (SEM 0.011), $P<0 \cdot 05$ ).
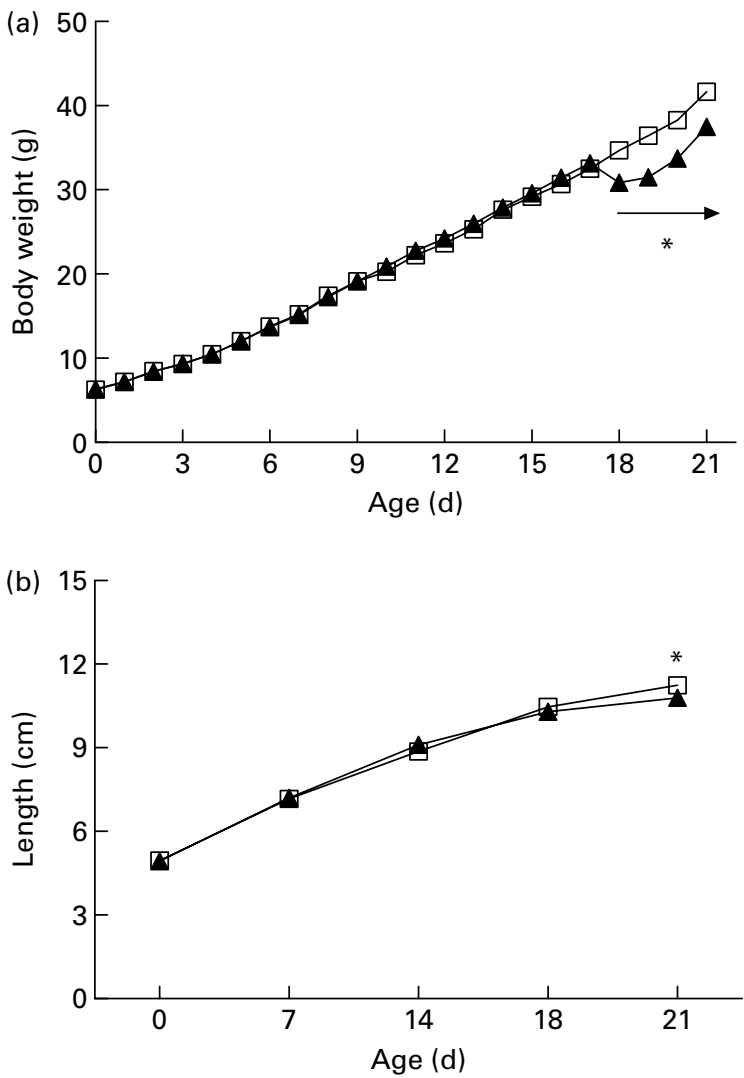

Fig. 1. (a) Body weight and (b) length during lactation of pups that were normally breast-fed for $21 \mathrm{~d}$ (control, $\square$ ) and early weaned ( $\boldsymbol{\Lambda}$ ). Values are means with of twelve rats/group, with standard errors represented by vertica bars. ${ }^{*}$ Mean values were significantly different compared with those of the control group $(P<0.05)$. 

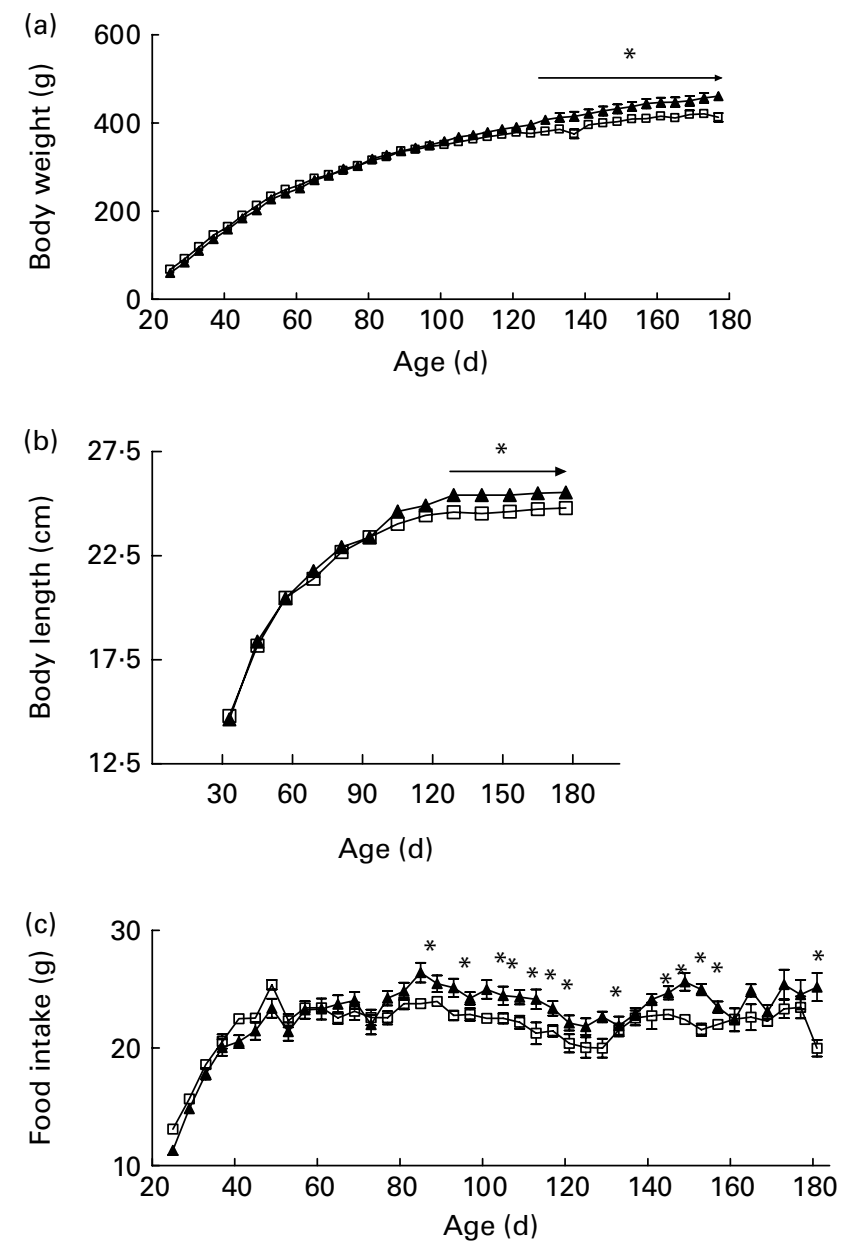

(d)

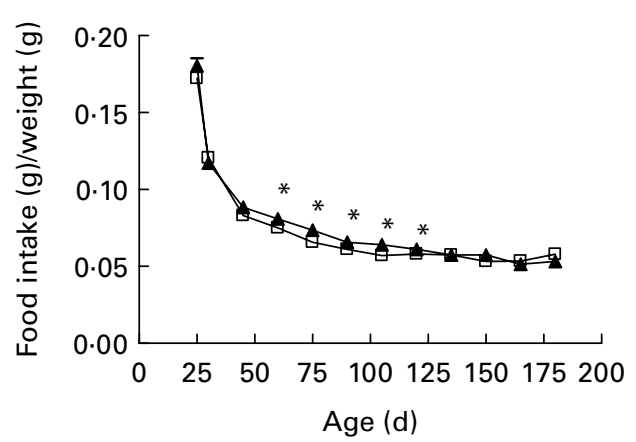

Fig. 2. (a) Body weight, (b) length, (c) food intake and (d) food intake/weight after weaning until pups of $180 \mathrm{~d}$ old were normally breast-fed for $21 \mathrm{~d}$ (control, $\square$ ) and early weaned $(\mathbf{\Lambda})$. Values are means of twelve rats/group with standard errors represented by vertical bars. * Mean values were significantly different compared with those of the control group $(P<0.05)$.

Table 2 shows the lipid profile of EW offspring in adult life. Serum TAG were higher in the EW group $(+96 \%, P<0.05)$ compared with the control group. However, total cholesterol, HDL-cholesterol, LDL-cholesterol or VLDL-cholesterol did not change significantly between the groups.

Protein levels of leptin signalling pathway components in the hypothalamus of adult EW rats are shown in Fig. 3. At 180 d, EW offspring presented lower JAK2 (-43\%; Fig. 3(b)), lower phosphorylated STAT3 (-32\% $P<0 \cdot 05$; Fig. 3(d)), lower phosphorylated STAT3:STAT3 ratio $(-24 \%, P<0.05$, data not shown) and higher SOCS3 ( $+97 \%, \quad P<0.05$; Fig. 3(e)) expressions compared to the controls, but no change in OB-R (Fig. 3(a)) and STAT3 (Fig. 3(c)) levels.

Concerning the glucose homeostasis of 21-d-old EW pups (Fig. 4), we observed lower glycaemia and insulinaemia ( -10 and $-20 \%, P<0.05$; Fig. 4(a) and (b), respectively) with unchanged adiponectin levels. In addition, IRI was lower ( $-30 \%, P<0.05$; Fig. $4(\mathrm{~d})$ ), suggesting that these animals were more sensitive to insulin. In adulthood, despite the normal serum insulin levels, EW rats displayed higher serum glucose $(+15 \%, \quad P<0.05$; Fig. 5(a)), higher IRI $(+29 \%, P<0.05$; Fig. $5(d))$ with lower serum adiponectin and PRL levels $(-59$, and $-38 \%, P<0.05$; Fig. 5(c); Fig. 5(e), respectively), which suggest an insulin resistance.

\section{Discussion}

The importance of mother-infant relationships in development, including the role of nutrition and physical contact, has been characterised from endocrine and neurochemical perspectives ${ }^{(39,40)}$. Milk is an important source of leptin that has been proposed to be required during a neonatal critical period for a normal postnatal development of hypothalamic pathways in the arcuate nucleus, which are involved in leptin signalling ${ }^{(41)}$. In mice, $\mathrm{EW}$ has been shown to affect the neuroendocrine response to stress ${ }^{(42)}$. As during lactation important cognitive and neurological development occurs, adverse environmental changes in this critical period of life can predispose the development of some diseases in adulthood $^{(14,43)}$. Nowadays, the time period dedicated to breast-feeding has decreased gradually, mainly because women are increasingly participating in the labour market.

The metabolic syndrome is defined as a set of at least three risk factors to CVD, such as central obesity, higher blood pressure, hypertriacylglycerolaemia, HDL-cholesterol reduction and insulin resistance ${ }^{(44)}$. The present study analysed the consequences of precocious weaning with no maternal separation or using pharmacological substances upon the programming of the body adiposity, glucose homeostasis, and hormone and lipid profiles in juvenile and adult

Table 1. Body composition and leptinaemia of control (C) and early-weaned (EW) offspring at 21 and $180 \mathrm{~d}$

(Mean values with their standard errors, $n 12$ )

\begin{tabular}{|c|c|c|c|c|c|}
\hline & \multirow[b]{2}{*}{ Groups } & \multicolumn{2}{|c|}{$21 \mathrm{~d}$ old } & \multicolumn{2}{|c|}{$180 \mathrm{~d}$ old } \\
\hline & & Mean & SEM & Mean & SEM \\
\hline \multirow{2}{*}{$\begin{array}{l}\text { Total body } \\
\text { fat }(\%)\end{array}$} & C & $9 \cdot 657$ & 0.5274 & $11 \cdot 24$ & 0.9766 \\
\hline & EW & $6 \cdot 790^{*}$ & 0.5118 & $15 \cdot 28^{*}$ & 1.109 \\
\hline \multirow{2}{*}{$\begin{array}{r}\text { Visceral fat } \\
\text { mass }(\mathrm{g})\end{array}$} & C & 0.3952 & 0.04196 & $10 \cdot 83$ & 1.256 \\
\hline & EW & $0.2349^{*}$ & 0.01151 & $19.94^{*}$ & $2 \cdot 788$ \\
\hline \multirow{2}{*}{$\begin{array}{l}\text { Total body } \\
\text { protein (\%) }\end{array}$} & C & 12.03 & 0.5553 & 8.036 & 0.6522 \\
\hline & EW & $16 \cdot 86^{*}$ & 1.028 & $6 \cdot 236^{*}$ & 0.4613 \\
\hline \multirow[t]{2}{*}{ Leptin (ng/ml) } & C & $2 \cdot 372$ & 0.2314 & 1.926 & 0.2466 \\
\hline & EW & $0.6343^{\star}$ & 0.1092 & $5 \cdot 490^{*}$ & 1.296 \\
\hline
\end{tabular}

${ }^{\star}$ Mean values were significantly different from those of the control group $(P<0.05)$. 
Table 2. Lipid profile of adult control (C) and early-weaned (EW) offspring

(Mean values with their standard errors, $n$ 12)

\begin{tabular}{lllr}
\hline & & \multicolumn{2}{c}{$180 \mathrm{~d}$ old } \\
\cline { 3 - 4 } & Groups & Mean & SEM \\
\hline Total cholesterol (mg/l) & C & $773 \cdot 3$ & $28 \cdot 0$ \\
& EW & $793 \cdot 6$ & $18 \cdot 2$ \\
HDL-cholesterol (mg/l) & C & $200 \cdot 8$ & $4 \cdot 0$ \\
& EW & $220 \cdot 0$ & $8 \cdot 8$ \\
LDL-cholesterol (mg/l) & C & $454 \cdot 2$ & $25 \cdot 2$ \\
& EW & $406 \cdot 7$ & $25 \cdot 3$ \\
TAG (mg/l) & C & $396 \cdot 9$ & $25 \cdot 2$ \\
& EW & $777 \cdot 7^{\star}$ & $75 \cdot 5$ \\
VLDL-cholesterol (mg/l) & C & $115 \cdot 4$ & $9 \cdot 0$ \\
& EW & $156 \cdot 2$ & $15 \cdot 2$
\end{tabular}

* Mean value was significantly different from those of the control group $(P<0.05)$

rats, in order to investigate the possible changes in some parameters directly associated with the metabolic syndrome.

At $21 \mathrm{~d}$, we showed that EW caused lower body weight, length, VFM, total body fat, hypoglycaemia and hypoinsulinaemia, all changes linked to malnutrition status. When the bandage was introduced to interrupt lactation, solid food was provided inside the cage, and the animals were already able to drink water in the bottle. This reinforces the importance of milk ingestion even at the last $3 \mathrm{~d}$ of lactation. In this moment, EW offspring seems to have normal insulin sensitivity since the IRI was lower. However, at $180 \mathrm{~d}$, those animals displayed overweight, higher total and visceral adiposity, higher serum levels of TAG and glucose as well as a higher IRI, which are components of the metabolic syndrome. Serum insulin levels were inappropriately unchanged, also suggesting a pancreatic $\beta$-cell failure. Some studies show that malnutrition caused by a large litter (eighteen pups) during all the suckling period reduces body-weight gain and adiposity ${ }^{(45)}$, and increases circulating adiponectin in adulthood ${ }^{(46)}$. However, in the present study, EW programmed for overweight and insulin resistance; it is possible that these contradictory findings were due to the intensity of undernutrition. In those studies, authors used an experimental model of moderate undernutrition, because despite increasing the competition among the pups, they still drank maternal milk, the opposite of our experimental model that is characterised by a severe malnutrition, because the pups did not drink maternal milk in the last $3 \mathrm{~d}$ of lactation.

At $21 \mathrm{~d}$, EW offspring showed lower serum leptin concentration, and this could imprint those animals for central leptin resistance and obesity. Previously, we showed that both maternal energy malnutrition during lactation and maternal hypoprolactinaemia caused by bromocriptine administration at the end of lactation (an EW experimental model) cause malnutrition of the pups at weaning ${ }^{(16,19)}$, and (a)
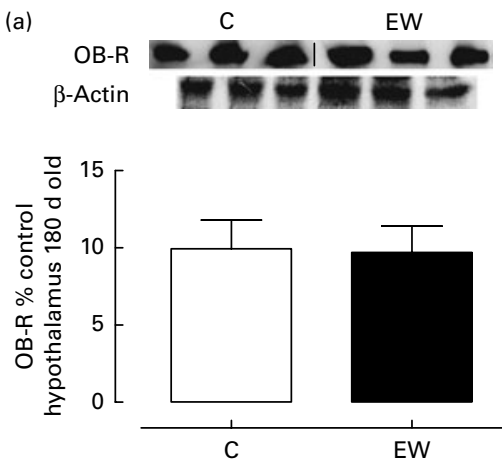

(b)
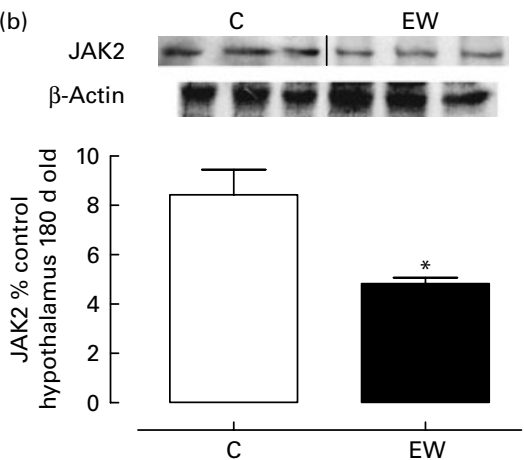

(c)
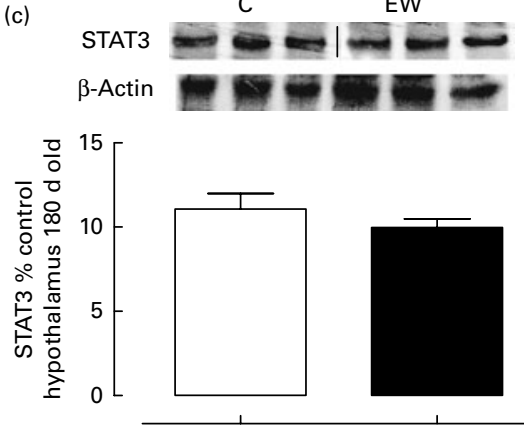

(d)
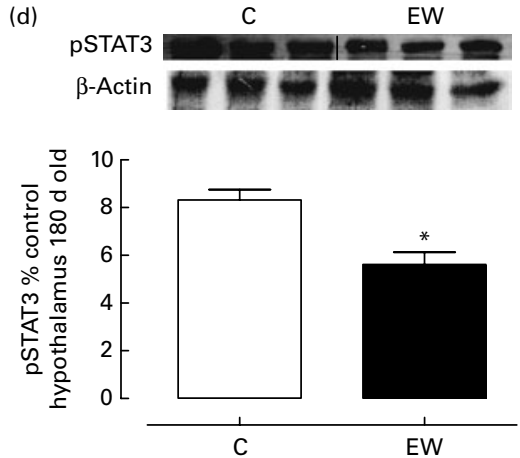

(e)
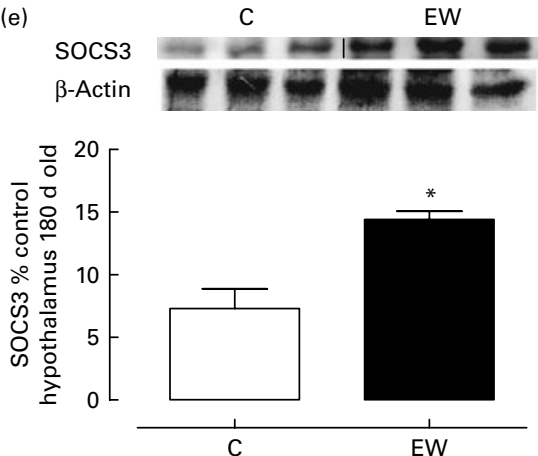

Fig. 3. Homogenates of the hypothalamus from the control (C) and early-weaned (EW) groups at $180 \mathrm{~d}$ were obtained, and (a) OB-R ( $n$ 6), (b) janus tyrosine kinase 2 (JAK2) $(n 6)$, (c) signal transducer and activator of transcription 3 (STAT3) ( $n$ 6), (d) phosphorylated STAT (pSTAT) ( $n$ 6) and (e) suppressor of cytokine signalling 3 (SOCS3) $(n 6)$ detections were performed by Western blotting. OB-R, JAK2, STAT3, pSTAT and SOCS3 contents were quantified by scanning densitometry of bands and are expressed as relative (\%) to the control group. Actin content was used as the control loading. A representative experiment is shown from two independent experiments. Values are means with standard errors, represented by vertical bars. * Mean values were significantly different from those of the control group $(P<0.05)$. 

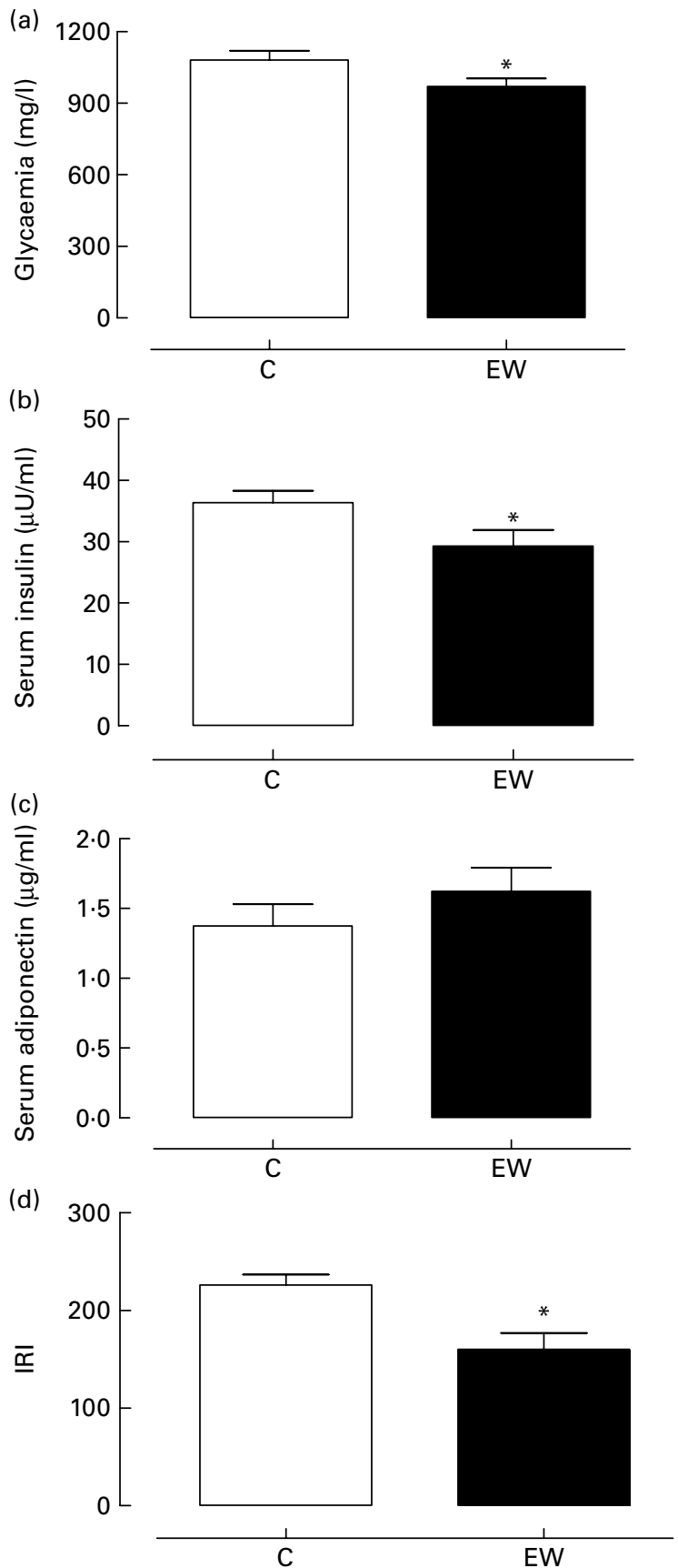

Fig. 4. (a) Serum glucose, (b) insulin, (c) adiponectin levels and (d) insulin resistance index (IRI) of 21-d-old offspring that were normally breast-fed for $21 \mathrm{~d}$ (control; C) and early weaned (EW). Values are means of twelve rats/group with standard errors represented by vertical bars. * Mean values were significantly different compared with those of the control group $(P<0.05)$.

programme for higher body-weight gain and central leptin resistance ${ }^{(17,20)}$. In both models, there seems to be a higher transfer of leptin from the mothers to the pups through the $\operatorname{milk}^{(19,47)}$. On the other hand, oral leptin treatment of suckling pups, equivalent to five times the amount of leptin normally ingested from maternal milk, was related to the prevention of later overweight/obesity ${ }^{(48)}$. In addition, Attig et al. ${ }^{(49)}$, using an antagonist to a leptin receptor during lactation, showed that the offspring is also programmed for obesity and leptin resistance. Thus, it seems that the correct leptin serum concentration and also the nutritional status during lactation are necessary for a normal leptin action and adipogenesis.

As early-weaned rats presented hyperphagia, higher adiposity and serum leptin levels in adult life, we decided to analyse the leptin signalling pathway in the hypothalamus. In fact, despite normal OB-R and STAT3 contents being detected, those animals exhibited lower JAK2, lower pSTAT and higher SOCS3 levels, which indicate a development of hypothalamic leptin resistance. Additionally, postnatal overfeeding caused by litter size reduction leads to the same mechanism in adult animals (lower JAK2 and pSTAT and higher SOCS3 expression), also suggesting central leptin resistance ${ }^{(50)}$. Thus, an adequate milk supply is an important factor responsible for a normal leptin action at the hypothalamic level.

Recently, it has been demonstrated that serum leptin adjusted for body fat in humans can be another criterion to evaluate the metabolic syndrome ${ }^{(51)}$. It seems that leptin production by adipose tissue is decreased in obese subjects, suggesting a relative leptin deficiency associated with advanced stages of the metabolic syndrome. In the present study, this relative deficiency was observed in adult EW rats since they showed a lower leptin:body fat ratio, corroborating the hypothesis that adipose tissue in obesity is dysfunctional.

Some studies have shown that higher body visceral fat is a risk factor to insulin resistance and other metabolic disorders in humans ${ }^{(52,53)}$ and rodents ${ }^{(54,55)}$. On the other hand, adiponectin levels have been associated with higher insulin sensitivity $^{(56,57)}$, and its level is inverse to total body adiposity ${ }^{(58)}$. So, it is possible that hyperglycaemia and hypoadiponectinaemia found in 180-d-old EW offspring, even with a normal serum insulin, may be due to its higher body fat and could be the beginning of insulin resistance. Changes in glucose homeostasis in adult life, such as lower insulin secretion ${ }^{(59,60)}$, changes in insulin sensitivity ${ }^{(12,61)}$, higher glucogenolysis ${ }^{(62)}$, lower $\beta$-cell quantity and pancreatic content of insulin ${ }^{(63)}$ are associated with protein malnutrition in critical periods of life. Moreover, PRL modulates the proliferation of pancreatic $\beta$-cells and the consequent lowering of glycaemia ${ }^{(64)}$. The fact that programmed EW rats had lower serum PRL could explain why they have an inappropriate response of insulin to hyperglycaemia have shown were adults, perhaps because they have an impairment on the development of pancreatic $\beta$-cells, Recently, we have shown that maternal hypoprolactinaemia for the last $3 \mathrm{~d}$ of lactation programmes for insulin resistance and lower serum PRL in their adult offspring ${ }^{(22)}$.

Concerning the lipid profile, besides no important change in total cholesterol, HDL-cholesterol, LDL-cholesterol or VLDL cholesterol, the hypertriacylglycerolaemia of adult EW offspring may indicate higher atherogenesis risk ${ }^{(65)}$, which suggests a higher risk of developing CVD. In fact, there is an association of low birth weight with dyslipidaemia and hypertension in adulthood ${ }^{(66)}$. In the present model, persistent hyperphagia could contribute to the high TAG levels. Previously, we showed that neonatal hyperleptinaemia programmed for higher food intake and hypertriacylglycerols ${ }^{(67)}$. 
(a)

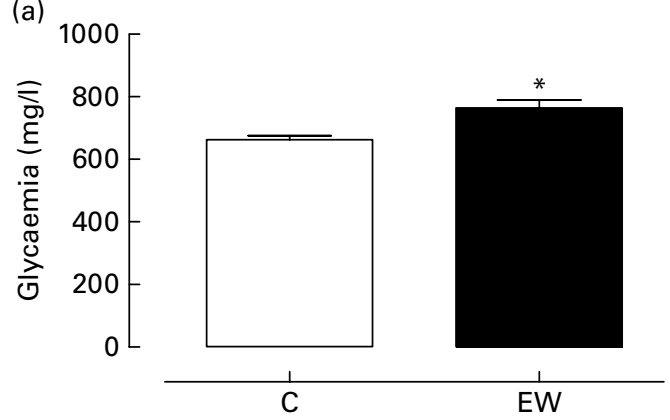

(b)

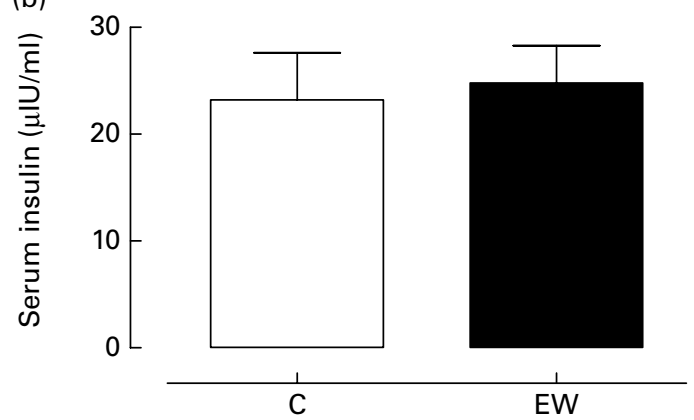

(c)

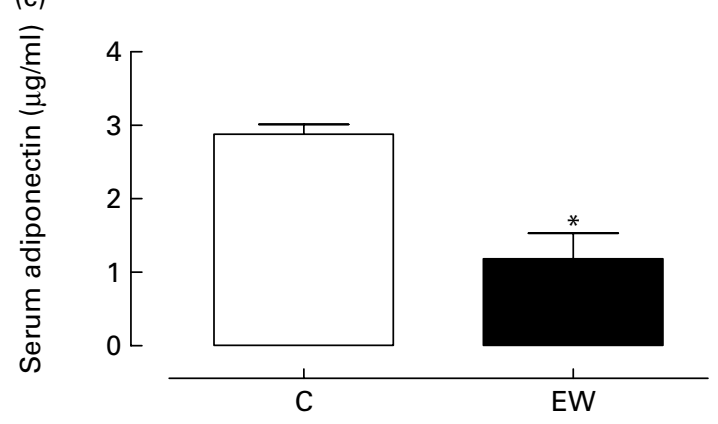

(d)

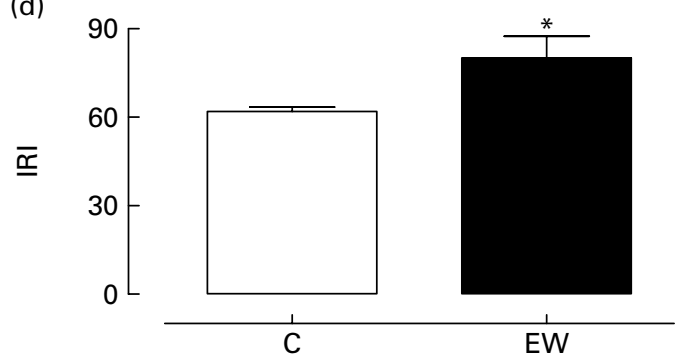

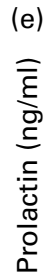

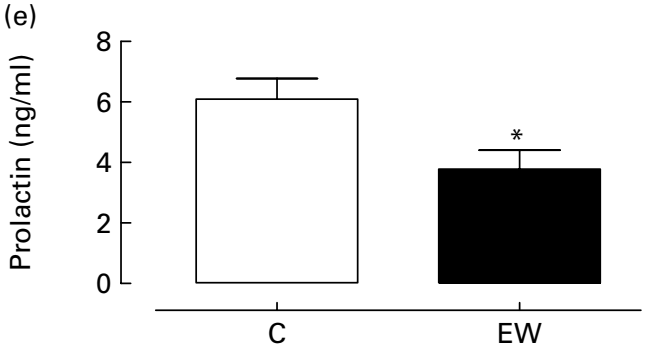

Fig. 5. (a) Glycaemia, (b) insulinaemia, (c) adiponectinaemia, (d) insulin resistance index (IRI) and (e) prolactinaemia of 180-d-old offspring that were normally breast-fed for $21 \mathrm{~d}$ (control; C) and early weaned (EW). Values are means of twelve rats/group with standard errors represented by vertical bars. * Mean values were significantly different compared with those of the control group $(P<0.05)$.
Despite some similarities (higher total and visceral fat, hypertriacylglycerolaemia), EW differs from the PRL inhibition model in relation to cholesterol and HDL-cholesterol levels. It seems that PRL suppression is more deleterious for the lipid profile than the EW.

In summary, the amount of our data provides evidence that EW leads to the late development of the metabolic syndrome as well as central leptin resistance. Our experimental model reinforces the idea that postnatal malnutrition caused by shortening lactation is important for the metabolic programming of future diseases, even when no pharmacological treatment is used.

\section{Acknowledgements}

The present study was supported by the National Council for Scientific and Technological Development (Conselho Nacional de Desenvolvimento Científico e Tecnológico - CNPq), the Carlos Chagas Filho Research Foundation of the State of Rio de Janeiro (Fundação Carlos Chagas Filho de Amparo à Pesquisa do Estado do Rio de Janeiro - FAPERJ) and Coordination for the Enhancement of Higher Education Personnel (Coordenação de Aperfeiçoamento de Pessoal de Nível Superior - CAPES). N. d. S. L. was recipient of a FAPERJ fellowship, and E. d. O. was recipient of a CAPES fellowship. The authors are grateful to Antonio CM de Sá, Vania Pinto and Ana Maria B Coutinho from Laboratory of Lipids (LabLip, UERJ) for lipid profile determination. We also thank Mr Carlos Roberto, Miss Monica Moura and Mr Luciano Santos for their technical assistance. The authors declare no conflict of interest. P. C. L., E. G. d. M. and M. C. F. P. designed the study and wrote the protocol and manuscript. N. d. S. L., J. F. N. N. and E. d. O. were responsible for animal programming, biochemical and molecular procedures. All authors contributed to and approved the final manuscript.

\section{References}

1. WHO (2002) The Optimal Duration of Exclusive Breastfeeding. Geneva: World Health Organization.

2. Harder T, Bergmann R, Kallischnigg G, et al. (2005) Duration of breastfeeding and risk of overweight: a meta-analysis. $\mathrm{Am}$ J Epidemiol 162, 397-403.

3. WHO (2003) Global Strategy for Infant and Young Child Feeding. Geneva: World Health Organization.

4. Barker DJ, Martyn CN, Osmond C, et al. (1993) Growth in utero and serum cholesterol concentrations in adult life. BMJ 11, 1524-1527.

5. de Oliveira Cravo C, Teixeira CV, Passos MC, et al. (2002) Leptin treatment during the neonatal period is associated with higher food intake and adult body weight in rats. Horm Metab Res 34, 400-405.

6. Dutra SC, Passos MC, Lisboa PC, et al. (2003) Liver deiodinase activity is increased in adult rats whose mothers were submitted to malnutrition during lactation. Horm Metab Res 35, 268-270.

7. Vicente LL, de Moura EG, Lisboa PC, et al. (2004) Malnutrition during lactation in rats is associated with higher expression of leptin receptor in the pituitary of adult offspring. Nutrition 20, 924-928. 
8. Toste FP, de Moura EG, Lisboa PC, et al. (2006) Neonatal leptin treatment programmes leptin hypothalamic resistance and intermediary metabolic parameters in adult rats. $\mathrm{Br} \mathrm{J}$ Nutr 95, 830-837.

9. de Moura EG, Lisboa PC, Custodio CM, et al. (2007) Malnutrition during lactation changes growth hormone mRNA expression in offspring at weaning and in adulthood. $J$ Nutr Biochem 18, 134-139.

10. Trevenzoli IH, Valle MM, Machado FB, et al. (2007) Neonatal hyperleptinaemia programmes adrenal medullary function in adult rats: effects on cardiovascular parameters. $J$ Physiol 580, 629-637.

11. Lisboa PC, Fagundes ATS, Denolato ATA, et al. (2008) Neonatal low-protein diet changes deiodinase activities and pituitary TSH response to TRH in adult rats. Exp Biol Med (Maywood) 233, 57-63.

12. Fagundes AT, Moura EG, Passos MC, et al. (2009) Temporal evaluation of body composition, glucose homeostasis and lipid profile of male rats programmed by maternal protein restriction during lactation. Horm Metab Res 41, 866-873.

13. Rodrigues AL, de Moura EG, Passos MC, et al. (2009) Postnatal early overnutrition changes the leptin signalling pathway in the hypothalamic-pituitary-thyroid axis of young and adult rats. J Physiol 1, 2647-2661.

14. Barker DJ (2003) The developmental origins of adult disease. Eur J Epidemiol 18, 733-736.

15. Moura EG \& Passos MC (2005) Neonatal programming of body weight regulation and energetic metabolism. Biosci Rep 25, 251-269.

16. de Moura EG, Lisboa PC \& Passos MC (2008) Neonatal programming of neuroimmunomodulation - role of adipocytokines and neuropeptides. Neuroimmunomodulation 15, 176-188.

17. Passos M, Ramos CF \& Moura EG (2000) Short and long term effects of malnutrition in rats during lactation on the body weight of offspring. Nutr Res 20, 1603-1612.

18. Passos MC, Vicente LL, Lisboa PC, et al. (2004) Absence of anorectic effect to acute peripheral leptin treatment in adult rats whose mothers were malnourished during lactation. Horm Metab Res 36, 625-629.

19. Lisboa PC, Passos MC, Dutra SC, et al. (2006) Leptin and prolactin, but not corticosterone, modulate body weight and thyroid function in protein-malnourished lactating rats. Horm Metab Res 38, 295-299.

20. Bonomo IT, Lisboa PC, Passos MC, et al. (2005) Prolactin inhibition in lactating rats changes leptin transfer through the milk. Horm Metab Res 37, 220-225.

21. Bonomo IT, Lisboa PC, Pereira AR, et al. (2007) Prolactin inhibition in dams during lactation programs for overweight and leptin resistance in adult offspring. $J$ Endocrinol 192, 339-344

22. Moura EG, Bonomo IT, Nogueira-Neto JF, et al. (2009) Maternal prolactin inhibition during lactation programs for metabolic syndrome in adult progeny. $J$ Physiol 15, 4919-4929

23. Bonomo IT, Lisboa PC, Passos MC, et al. (2008) Prolactin inhibition at the end of lactation programs for a central hypothyroidism in adult rat. J Endocrinol 198, 331-337.

24. Palou M, Priego T, Sanchez J, et al. (2010) Moderate caloric restriction in lactating rats protects offspring against obesity and insulin resistance in later life. Endocrinology 151, $1030-1041$

25. Lee GH, Proenca R, Montez JM, et al. (1996) Abnormal splicing of the leptin receptor in diabetic mice. Nature 379, 632-635.
26. Vaisse C, Halaas JL, Horvath CM, et al. (1996) Leptin activation of STAT3 in the hypothalamus of wild-type and ob/ob mice but not db/db mice. Nature Genetics 14, 95-97.

27. Velloso LA, Araujo EP \& de Souza CT (2009) Diet-induced inflammation of the hypothalamus in obesity. Neuroimmunomodulation 15, 189-193.

28. Considine RV, Considine EL, Williams CJ, et al. (1996) The hypothalamic leptin receptor in humans: identification of incidental sequence polymorphisms and absence of the $\mathrm{db} / \mathrm{db}$ mouse and fa/fa rat mutations. Diabetes 45, 992-994.

29. Martin RL, Perez E, He YJ, et al. (2000) Leptin resistance is associated with hypothalamic leptin receptor mRNA and protein downregulation. Metabolism 49, 1479-1484.

30. Ahima RS \& Flier JS (2000) Adipose tissue as an endocrine organ. Trends Endocrinol Metab 11, 327-332.

31. Jéquier E (2002) Pathways to obesity. Int J Obes Relat Metab Disord 26, S12-S17.

32. Burguera B, Couce ME, Curran GL, et al. (2000) Obesity is associated with a decreased leptin transport across the blood-brain barrier in rats. Diabetes 49, 1219-1223

33. Banks WA (2001) Leptin transport across the blood-brain barrier: implications for the cause and treatment of obesity. Curr Pharm Des 7, 125-133.

34. Drummond GB (2009) Reporting ethical matters in The Journal of Physiology: standards and advice. J Physiol 587, 713-719.

35. Marques RG, Morales MM \& Petroianu A (2009) Brazilian law for scientific use of animals. Acta Cir Bras 24, 69-74.

36. Fagundes AT, Moura EG, Passos MC, et al. (2007) Maternal low-protein diet during lactation programmes body composition and glucose homeostasis in the adult rat offspring. Br J Nutr 98, 922-928.

37. Troina AA, Figueiredo MS, Moura EG, et al. (2010) Maternal flaxseed diet during lactation alters milk composition and programs the offspring body composition, lipid profile and sexual function. Food Chem Toxicol 48, 697-703.

38. Lowry OH, Rosebrough NJ, Farr AL, et al. (1951) Protein measurement with the Folin phenol reagent. $\mathrm{J} \mathrm{Biol} \mathrm{Chem}$ 193, 265-275.

39. Liu D, Caldji C, Sharma S, et al. (2000) Influence of neonatal rearing conditions on stress-induced adrenocorticotropin responses and norepinepherine release in the hypothalamic paraventricular nucleus. J Neuroendocrinol 12, 5-12.

40. Uriarte N, Breigeiron MK, Benetti F, et al. (2007) Effects of maternal care on the development, emotionality, and reproductive functions in male and female rats. Dev Psychobiol 49, 451-462.

41. Bouret SG, Draper SJ \& Simerly RB (2004) Formation of projection pathways from the arcuate nucleus of the hypothalamus to hypothalamic regions implicated in the neural control of feeding behavior in mice. $J$ Neurosci 24, 2797-2805.

42. Kikusui T, Nakamura K, Kakuma Y, et al. (2006) Early weaning augments neuroendocrine stress responses in mice. Behav Brain Res 175, 96-103.

43. Huang PL (2009) A comprehensive definition for metabolic syndrome. Dis Model Mech 2, 231-237.

44. Teixeira CV, Passos MCF, Ramos CF, et al. (2002) Leptin serum concentration, food intake and body weight in rats whose mothers were exposed to malnutrition during lactation. J Nutr Biochem 13, 493-498.

45. Velkoska E, Cole TJ, Dean RG, et al. (2008) Early undernutrition leads to long-lasting reductions in body weight and adiposity whereas increase intake increase cardiac fibrosis in male rats. $J$ Nutr 138, 1622-1627.

46. Prior LJ, Velkoska E, Watts R, et al. (2008) Undernutrition during suckling in rats elevates plasma adiponectin and its 
receptor in skeletal muscle regardless of diet composition: a protective effect? Int J Obes 32, 1585-1594.

47. Dorner G \& Plagemann A (1994) Perinatal hyperinsulinism as possible predisposing factor for diabetes mellitus, obesity and enhanced cardiovascular risk in later life. Horm Metab Res 26, 213-221.

48. Picó C, Oliver P, Sanchez J, et al. (2007) The intake of physiological doses of leptin during lactation in rats prevents obesity in later life. Int J Obes 31, 1199-1209.

49. Attig L, Solomon G, Ferezou J, et al. (2008) Early postnatal leptin blockage leads to a long-term leptin resistance and susceptibility to diet-induced obesity in rats. Int $J$ Obes (Lond) 32, 1153-1160.

50. Rodrigues AL, de Moura EG, Passos MCF, et al. (2010) Postnatal early overfeeding induces hypothalamic higher SOCS3 expression and lower STAT3 activity in adult rats. J Nutr Biochem (Epublication ahead of print version 19 March 2010).

51. Paz-Filho GJ, Volaco A, Suplicy HL, et al. (2009) Decrease in leptin production by the adipose tissue in obesity associated with severe metabolic syndrome. Arq Bras Endocrinol Metabol 53, 1088-1095.

52. Abate N, Garg A, Peshock RM, et al. (1995) Relationships of generalized and regional adiposity to insulin sensitivity in men. J Clin Invest 96, 88-98.

53. Seidell JC \& Bouchard C (1997) Visceral fat in relation to health: is it a major culprit or simply an innocent bystander? Int J Obes Relat Metab Disord 21, 626-631.

54. Barzilai N, She L, Liu L, et al. (1999) Decreased visceral adiposity accounts for leptin effect on hepatic but not peripheral insulin action. Am J Physiol 277, E291-E298.

55. Gabriely I, Ma XH, Yang XM, et al. (2002) Removal of visceral fat prevents insulin resistance and glucose intolerance of aging: an adipokine-mediated process? Diabetes 51, 2951-2958

56. Berg AH, Combs TP, Du X, et al. (2001) The adipocytesecreted protein Acrp30 enhances hepatic insulin action. Nat Med 7, 947-953.
57. Yamauchi T, Kamon J, Waki H, et al. (2001) The fat-derived hormone adiponectin reverses insulin resistance associated with both lipoatrophy and obesity. Nat Med 7, 941-946.

58. Arita Y, Kihara S, Ouchi N, et al. (1999) Paradoxical decrease of an adipose-specific protein, adiponectin, in obesity. Biochem Biophys Res Commun 257, 79-83.

59. Desai M, Byrne CD, Meeran K, et al. (1997) Regulation of hepatic enzymes and insulin levels in offspring of rat dams fed a reduced-protein diet. Am J Physiol 273, G899-G904.

60. Moura AS, Caldeira Filho JS, de Freitas Mathias PC, et al. (1997) Insulin secretion impairment and insulin sensitivity improvement in adult rats undernourished during early lactation. Res Commun Mol Pathol Pharmacol 96, 179-192.

61. Benyshek DC, Johnston CS \& Martin JF (2004) Post-natal diet determines insulin resistance in fetally malnourished, low birthweight rats (F1) but diet does not modify the insulin resistance of their offspring (F2). Life Sci 74, 3033-3041.

62. Burns SP, Desai M, Cohen RD, et al. (1997) Gluconeogenesis, glucose handling, and structural changes in livers of the adult offspring of rats partially deprived of protein during pregnancy and lactation. J Clin Invest 100, 1768-1774.

63. Bertin E, Gangnerau MN, Bailbe D, et al. (1999) Glucose metabolism and beta-cell mass in adult offspring of rats protein and/or energy restricted during the last week of pregnancy. Am J Physiol 277, E11-E17.

64. Ose K, Miyata K, Yoshioka K, et al. (2009) Effects of hyperprolactinemia on toxicological parameters and proliferation of islet cells in male rats. J Toxicol Sci 34, 151-162.

65. Després JP (1991) Lipoprotein metabolism in visceral obesity. Int J Obes 15, 45-52.

66. Fall CH, Osmond C, Barker DJ, et al. (1995) Fetal and infant growth and cardiovascular risk factors in women. BMJ $\mathbf{3 1 0}$ 428-432.

67. Toste FP, de Moura EG, Lisboa PC, et al. (2006) Neonatal leptin treatment programmes leptin hypothalamic resistance and intermediary metabolic parameters in adult rats. $\mathrm{Br} J$ Nutr 95, 830-837. 